\title{
Cost-Effectiveness of Varenicline Compared to Placebo as an Aid to Smoking Cessation in Patients with Cardiovascular Disease
}

\author{
Robert Hettle $^{*}, 1$, Koo Wilson ${ }^{2}$, Tunde Peter ${ }^{3}$, Juris Ezernieks ${ }^{4}$, Dieter Hack1 ${ }^{5}$ and Christopher Wolf ${ }^{6}$ \\ ${ }^{1}$ Health Economic Modelling Unit, HERON Evidence Development Ltd., Building 210a, Butterfield Technology and \\ Business Park, Stopsley, Luton LU2 8DL, UK \\ ${ }^{2}$ Pfizer Limited, IPC 5-G-27, Walton Oaks, Dorking Road, Walton-on-the-Hill, Surrey, KT20 7NS, UK \\ ${ }^{3}$ Pfizer Hungary, Budapest, Alkotás street 53., 1123, Hungary \\ ${ }^{4}$ Pfizer Deutschland GmbH, Linkstr. 10. Postfach 6101 94, D-1078, 5 Berlin. 10922 Berlin, Germany \\ ${ }^{5}$ Pfizer Corporation Austria Gesellschaft m.b.H., FN 126844k HG Wien, Floridsdorfer Hauptstrasse 1, A - 1210 Wien, \\ Austria \\ ${ }^{6}$ Medizinische Abteilung, Sozialmedizinisches Zentrum Ost-Donauspital, Langobardenstraße 122, 1220 Wien, Austria
}

\begin{abstract}
Background: Varenicline has been shown to be an effective and well-tolerated intervention for smoking cessation in smokers with stable cardiovascular disease (CVD). The objective of this study was to evaluate the costeffectiveness of varenicline and counselling compared to placebo and counselling based on extrapolating the results of a 52-week randomised controlled trial.

Method: A Markov model was developed to simulate the outcomes of smokers with CVD. Outcomes included major forms of CVD (e.g. Coronary Heart Disease [CHD]) and other key chronic conditions attributable to smoking (e.g. Lung Cancer). The lifetime costs, Life-Years gained (LY) and Quality-Adjusted Life Years (QALY) were evaluated from a payer's perspective in Austria, Hungary and Germany. Additional analyses included a societal perspective, disease subgroup, and both one-way and probabilistic sensitivity analyses (PSA). Costs and outcomes were discounted at 3\% per year.

Results: From a payer's perspective, the incremental cost-effectiveness ratio per LY (or QALY) gained was $€ 4112$ ( $€ 5$ 278), $€ 2507$ ( $€ 3$ 183), and $€ 4567$ ( $€ 5$ 867) for Austria, Hungary and Germany, respectively. Sub-group analyses demonstrated that smoking cessation in patients with CHD was more cost-effective than in patients with baseline stroke or peripheral vascular disease. Sensitivity analysis demonstrated that outcomes were not sensitive to modelling assumptions. Varenicline was less costly and more effective than placebo from a societal perspective, and more costly and more effective than placebo in all iterations of the payer PSA.

Conclusions: Varenicline is a cost-effective adjunct to counselling compared to counselling alone in patients with stable CVD.
\end{abstract}

Keywords: Smoking cessation, varencline, cardiovascular disease, cost-effectiveness.

\section{INTRODUCTION}

In 2002, the World Health Organization (WHO) estimated that within the European region, smoking and tobacco use accounted for approximately $12 \%$ of the total burden of Disability Adjusted Life Years (DALY), a measure of life years lost due to premature mortality and years lived in disability [1]. As a result, smoking accounted for approximately 18 million years of life lost, and was the second highest contributor in terms of the overall DALY burden behind high blood pressure (13\%) [1]. Of the 45 member countries of the WHO European region, smoking

*Address correspondence to this author at the Health Economic Modelling Unit, HERON Evidence Development Ltd., Building 210a, Butterfield Technology and Business Park, Stopsley, Luton LU2 8DL, UK; Tel: +44 (0)1582 433650; Fax: +44 (0)1582 433651;

E-mail: Robert.Hettle@heronhealth.com was the leading contributor in 31 member states including Austria (11.0\%), Hungary (20.9\%) and Germany (13.7\%). Despite measures to control tobacco use the effect of smoking on public health remains high.

In 2000 , the economic burden of smoking within the European Union (EU) was estimated in the region of $€ 97.7$ billion to $€ 130.31$ billion, equivalent to $1.04 \%$ to $1.39 \%$ of gross domestic product (GDP) [2]. Indirect costs accounted for half of the total economic cost. Newer members of the EU such as Hungary may lose the equivalent of $2.7 \%$ to $4 \%$ of their national GDP, courtesy of smoking [2]. This economic loss is felt by smokers and non-smokers, through higher insurance premiums and lost tax and contributions to benefit funds [2]. Overall, the burden of smoking affects many aspects of society. 
For patients with cardiovascular disease (CVD), the burden of smoking through increased disease and mortality can be severe. Tobacco dependence has been shown to cause endothelial cell injury, cell dysfunction and atherosclerosis, the main underlying physiologic process of most major forms of CVD [3]. A systematic review of 20 trials studying secondary prevention of coronary heart disease (CHD) found a $36 \%(95 \%$ CI $29 \%$ to $42 \%)$ relative reduction in the risk of all-cause mortality and a $32 \%(95 \%$ CI $18 \%$ to $43 \%)$ relative reduction in the incidence of myocardial infarction amongst smokers who successfully quit compared to those who did not. Overall, smoking cessation was found to be as effective in reducing mortality than alternative secondary prevention therapies, such as cholesterol lowering [4].

The findings of a recent European-wide survey of risk factors in patients with CVD, the European Action on Secondary and Primary Prevention through Intervention to Reduce Events (EUROASPIRE III) survey, highlighted that the management of smoking in clinical practice was not as effective as it could be. Results of the study found that $51.9 \%$ of respondents were smokers in the month prior to a coronary event [5]. Following the index event, the majority of patients received verbal $(90.7 \%)$ and/or written $(34.6 \%)$ advice to quit smoking, with a minority of patients further advised to seek professional or pharmacological support (14.3\%) [5]. As a result, 29.8\% of persistent smokers reported taking no action to stop smoking, alongside a further $11.2 \%$ who attempted but subsequently relapsed. Overall, the prevalence of smoking following the index event remained high $(17.2 \%)$ [5].

Studies such as EUROASPIRE [5], and more recently the European study on Cardiovascular Risk Prevention and Management in Usual Daily Practice (EURIKA) [6], have highlighted the need for better management of lifestyle risk factors in patients with CVD in primary care. Disappointingly, in countries such as Austria, Germany and Hungary, the prevalence of smoking following an index event is reportedly high $(23.8 \%$ [6], and $17.2 \%$ and $16.6 \%$ [5], respectively). This high incidence may be a result of inadequate levels of prevention management, which in part may be due to physician perceived barriers to treatment, including concerns over prescription costs and lack of motivation [7].

Strategies to support individuals who are willing to quit include intervention by pharmacotherapy and behaviour counselling. Various pharmacotherapies are currently available including Nicotine Replacement Therapy, Bupropion and more recent treatments such as the nicotinic acetylcholine receptor partial agonist; varenicline. A recent 52-week, double-blind, placebo-controlled, randomised trial evaluated varenicline and counselling versus placebo and counselling in smokers with stable CVD [8]. Trial participants consisted of smokers who were willing to attempt cessation supported by pharmacological support, having experienced no CVD events during the two months prior to smoking cessation treatment, and with either a history of CHD or history of revascularisations. The results of this study demonstrated that varenicline was effective for smoking cessation and well tolerated in patients with CVD $[8]$.
From an economic perspective, over 20 studies have previously demonstrated that varenicline is a cost-effective intervention for smoking cessation from both the health care payer and employers perspective, with incremental costeffectiveness ratio's ranging from dominance to $€ 18582$ per Quality Adjusted Life Year (QALY) gained [9]. Recently, a de novo economic evaluation of smoking cessation treatment in patients with CVD in Spain, Portugal, Belgium and Italy extended this evidence base to those with pre-existing conditions and who are at high risk of morbidity and mortality [10]. The results of this study highlighted the costeffectiveness of varenicline plus brief counselling compared to placebo and brief counselling [10]. In settings such as Austria, Hungary and Germany, the cost-effectiveness of pharmacotherapy based smoking cessation in patients with CVD in primary care has not previously been reported.

The aim of this study was to evaluate the costeffectiveness of varenicline and counselling versus placebo and counselling in German, Austrian and Hungarian smokers with stable CVD. In a similar fashion to Wilson et al., a decision analytical model was developed to extrapolate the results of the previously described randomised placebocontrolled trial $[8,10]$. The trial population comprised those with stable disease having no events in the two months prior to treatment. Those with a history of CHD and revascularisations were included. The benefits of abstinence through pharmacological intervention were evaluated over the course of a lifetime.

\section{METHODS}

\section{Summary}

The structure of the model follows that of the previously published Benefits of Smoking Cessation on Outcomes (BENESCO) model [11], adapted to better evaluate patients with stable CVD. A cohort-based Markov model comprising 18 health states representing all major forms of CVD, in addition to other non-CVD related conditions attributable to smoking (referred as key conditions hereafter) was developed. Health states for key smoking-attributable conditions comprised of lung cancer, chronic obstructive pulmonary disease (COPD) and mouth cancer. Various sources of data were used to populate the model, including country-specific data and data assumed common to all countries.

The length of each cycle in the Markov model was set to 1 -year, chosen to represent the anticipated time between mutually exclusive events. Results were calculated using a lifetime horizon of 65 years, chosen to fully appreciate the benefits in preventing secondary chronic conditions that require lifelong care. Any subject in the model who reached the age of 100 years, died in the following cycle.

Major forms of CVD were represented by three diseases; Stroke, CHD and peripheral vascular disease (PVD). Each disease was represented in the model by health states for acute events and stable conditions (i.e. having experienced previous events). New events within the model included repeat events that followed the cohort's previous event history, such as secondary stroke in patients with a history of a stroke, and events across diseases such as CHD in patients with a history of stroke. The characteristics of each disease 
was based on the population in the clinical trial [8]. In brief, the CHD disease group included subjects with a history of myocardial infarction and angina pectoris; the stroke group included subjects with a history of cerebrovascular disease; and subjects with a history of peripheral arterial disease were classified in the PVD group.

The cohort entered the model as smokers with stable CVD, with further stratification by age (35-64 years, 65+ years) and gender. Subjects within each disease were associated with unique risks and clinical pathways related to the pathology of their underlying condition.

\section{Clinical Pathway}

The risk of disease and mortality was dependent on current disease state, age, gender and smoking status. For lung cancer, mouth cancer and COPD, the risk of disease and mortality were the same across all subjects. Subject's with stable CHD, PVD or stroke, could suffer a single non-fatal acute stroke or CHD event in the model, remain in the stable disease state, develop a key smoking-attributable disease or die (all-causes) in a given cycle. Fig. (1) provides a schematic of the model.

Each state in the model was associated with exclusive costs, utility weights and mortality risks. Subject's who suffered a non-fatal acute event incurred increased costs and risk of mortality, alongside a reduction in quality of life related to that condition. Those patients who survived entered a new health state after one-cycle. For patients who entered the model with CHD or stroke, the subsequent year health states represented secondary stable conditions (i.e. those having survived two stroke events) or co-morbidity in terms of previous CHD and stroke conditions (i.e. stable CHD and stroke). For patients with PVD, the subsequent year health state was represented as a co-morbid state for PVD and CHD or PVD and stroke.

All subjects regardless of CVD health status could transition to any of the key smoking-attributable health states during any cycle in the model. These key conditions were assumed to be chronic, with subjects remaining within their chronic health state until death.

\section{Smoking Cessation Treatment}

At baseline, subjects were assigned to treatment with varenicline and counselling, or placebo and counselling with formulations based on the varenicline and placebo arms of the clinical trial [8]. In brief, pharmacotherapy included varenicline at $0.5 \mathrm{mg}$ once a day for 3 days, $0.5 \mathrm{mg}$ twice a day for 4 days followed by $1.0 \mathrm{mg}$ twice a day for total of 12 weeks. Counselling consisted of 12 weekly clinic visits lasting a maximum of 10 minutes, in addition to a single telephone call 3 days after the first visit. For the purpose of this study, the endpoint of interest was the measure of continuous abstinence from week 9 through 52, verified by a measurement of expired air carbon monoxide of less than or equal to 10 parts per million [8]. In the model, treatments that have a higher rate of abstinence produce fewer smokers and more quitters than less efficacious treatments.

Subjects who achieved abstinence at the end of the first cycle were classified as former smokers; with those unsuccessful classified as current smokers. During each proceeding cycle, patients could relapse and resume smoking thereby retaining the cumulative benefit of smoking

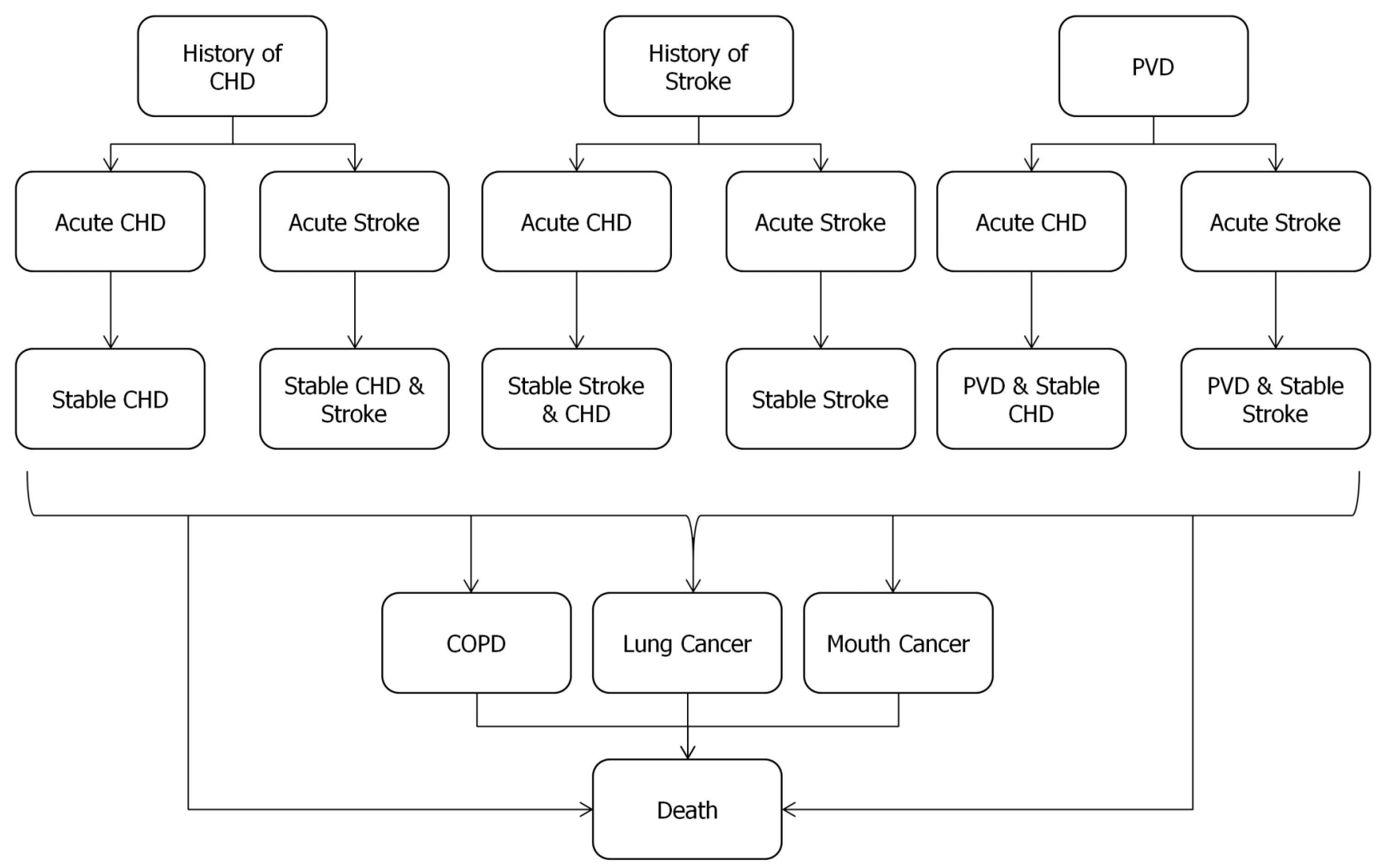

Fig. (1). Model schematic. 
cessation until the point of relapse. Further disease risks were adjusted based on their smoking status. Only one quit attempt was permitted during the life of the model, assumed at baseline.

\section{Data Assumed Common to All Country Settings}

Various parameters within the model were assumed common to all countries, including baseline characteristics, efficacy of treatment, the risk of disease and mortality, relative risk of events based on smoking status, and the risk of relapses. Common parameters were identified in cases where a lack of disease-specific data relative to Austria, Germany and Hungary was found, or in the case of treatment effect, where country differences were not felt to influence the effectiveness of an intervention over placebo.

At baseline, the proportion of subjects by disease, agegroup and gender were based on the clinical characteristics of patients randomised to the varenicline arm of the clinical trial [8], with $31 \%$ of subjects having stable CHD, $8 \%$ having stable stroke and $61 \%$ having PVD. The patient distribution by age was $82 \%$ between 35 to 64 years and $18 \%$ aged 65 years or older. The gender distribution was $75 \%$ male and $25 \%$ female [8].

Treatment effect was based on the measure of continuous abstinence from week 9 through 52, based on the varenicline and placebo arms of the clinical trial [8]. The results of this study demonstrated that varenicline in addition to counselling was more efficacious than placebo plus counselling, with $19.2 \%$ of patients achieving continuous abstinence up to week $52(\mathrm{~N}=355)$ versus $7.2 \%(\mathrm{~N}=359)$ of patients receiving placebo [8].

In the absence of country-specific and smoking-specific data, estimates of risk were obtained from external data sources to Germany, Austria, and Hungary. These included the general population risks of mortality, CVD and all key smoking-attributable conditions. The data provided by these sources were averaged across individuals who smoke, previously smoked and never smoked. To determine the risk of events by smoking status, the incidence of CVD in the general population was transformed using the classical attributable-risk formula, as applied in the SAMMEC (Smoking-Attributable Mortality, Morbidity, and Economic Cost) and BENESCO models [11, 12]. The function is defined as follows:

$\operatorname{risk}_{A l l}=\operatorname{risk}_{n s} \times\left(\right.$ prev $_{n s}+$ prev $_{f s} \times R R_{f s}+$ prev $\left._{s m} \times R R_{s m}\right)$

where

prev $_{x}$ is the prevalence of smoking status $\mathrm{x}$

$R R_{x}$ is the relative risk of the outcome in smoking status $\mathrm{x}$ relative to never smokers

risk ${ }_{x}$ is the absolute risk of the outcome per year in smoking status $\mathrm{X}$

$\mathrm{x}$ denotes smoker (sm), former smoker (fs), never smoker (ns) or all (all) populations of patients with CVD.

For events directly related to the cohort's previous disease history (i.e. stroke in subject's with stable stroke), the risk of mortality, acute CHD in subject's with stable
CHD, acute stroke and all key smoking-attributable events, were based on incidence and prevalence statistics from the UK general population $[13,14]$. Transformations from general to smoking-specific event rates were undertaken using the relative risk of an event based on smoking status, obtained from the Cancer Prevention Study II, a large longitudinal study of smoking-related mortality risk in the US [15]. The proportional impact of each status was obtained through country-specific smoking prevalence rates.

For events across diseases, such as CHD in subjects with stable stroke, the risk of disease was obtained directly from the published literature. In all cases, risk values were assumed independent of age and gender. The annual risk of CHD and stroke in subject's with PVD was 19.3\% for current smokers and $13.7 \%$ for former smokers [16]. For those with stable CHD, the annual risk of stroke was $3.9 \%$ in current smokers and $2 \%$ in former smokers [17]. For those with stable stroke, the annual risk of CHD was assumed to be four-thirds the risk of CHD in patients without a history of stroke, regardless of smoking status [18].

Following a successful quit attempt, subjects could relapse and resume smoking during any cycle. The risk of such events was assumed to decline over time. The annual risk of a relapse was $6.3 \%$ up to five years following abstinence [19], 2.0\% for years 6-10 [20] and 1.0\% for abstinence beyond 11 years [20].

\section{Country-Specific Data}

Factors considered specific to each country were identified based on the availability of data, and the author's judgement as to whether parameters may differ significantly across settings. The factors meeting these criteria included the cost of intervention, cost of disease management, smoking prevalence rates, and the all-cause risk of mortality.

The cost of smoking cessation treatment was based on resource use for pharmacotherapy and counselling, defined in the study protocol of the clinical trial [8], multiplied by the local unit cost of treatment for each setting. In the Austrian, German and Hungarian settings, the cost of varenicline and brief counselling was $€ 1261, € 1168$ and $€ 252$, respectively, compared to $€ 866$ for placebo and counselling in Austria and Germany and $€ 13$ in Hungary. In the absence of data, the cost of counselling in Austria was assumed the same as in Germany.

The cost of disease management for each country and event in the model was collected through a variety of sources including national data registries and published studies. Where the cost of disease management could not be identified, estimates were derived based on the available costs for other health states in the model. The number of primary data sources available varied by country. Where health state costs were missing for all countries, consistent cost assumptions were applied. Table $\mathbf{1}$ provides a summary of the cost by health state in the model.

\section{Common Cost Assumptions}

In all settings, the cost of managing stable disease in subjects who experienced co- morbidities: stroke and CHD, PVD and CHD, and PVD and stroke could not be sourced, and therefore were estimated based on the cost of managing 
stable disease in each form of CVD that made-up the comorbid state. The annual cost of care following a CHD event in subjects with stable stroke (and stroke in subjects with stable CHD) was assumed equal to the most expensive health state of stable stroke and stable CHD. The cost of PVD with either stroke or CHD, was equal to the cost of PVD in each country multiplied by the ratio of costs between managing PVD, and PVD and CHD, as reported in a large claims database analysis in the United States (US) [21].

From a societal perspective, the cost of lost productivity due to premature mortality was calculated based on the average earnings for those between 35 and 64 years old, reported in each country $[22,23]$. Productivity in those aged 65 years or older was zero, assuming the cohort retired aged 65 years.

\section{Costs from the German Setting}

For Germany, all other CVD and smoking-attributable health state costs were identified (Table 1). Sources of data included diagnosis related groups and national tariff schemes.

\section{Costs from the Austrian Setting}

In Austria, the cost of stable CHD and stable stroke could not be sourced. In the absence of data, the cost of managing stable disease was estimated based on the available acute costs, multiplied by the relative cost of managing stable disease compared to acute care, for the matching health state in Germany:

$\cos t_{A}($ stable $)=\cos t_{A}($ acute $) \times \frac{\cos t_{G}(\text { stable })}{\cos t_{G}(\text { acute })}$

where,

$\cos t_{x}($ stable $)$ is the cost of stable CHD or stroke care in Austria (A) or Germany (G),

$\cos t_{x}$ (acute) is the cost of acute CHD or stroke care in Austria (A) or Germany (G).

In doing so, we assumed that the relative cost of acute CVD to stable CVD in Austria is equivalent to the same comparison in Germany. All other costs were identified from the literature, and/or local sources (Table 1).

\section{Costs from the Hungarian Setting}

In Hungary, there exist limited resources to estimate the cost of disease management from the perspective of the healthcare provider. Health care costs for a variety of health states were recovered from the National Health Insurance Fund databases, with costs reflecting drug, medical device, inpatient and outpatient care. These annual costs included Lung cancer, COPD, acute and stable CHD, and acute and stable stroke. Missing costs included PVD and mouth cancer.

In the absence of data, the missing health state costs were estimated by adjusting the cost of a related health state in Hungary, by the ratio of costs between the related state and the missing health states in Germany and Austria. For example, the cost of PVD was based on the cost of stable CHD in Hungary, multiplied by the ratio of costs between PVD and stable CHD, reported in Austria and Germany. This led to a PVD-to-stable CHD cost ratio of 1.54, and an annual PVD cost of $€ 922$ ( $€ 593 \times 1.54)$. A similar approach was taken for mouth cancer, based on the average relative cost of German and Austrian mouth to lung cancer costs (ratio $=0.81$ ), multiplied by the cost of lung cancer in Hungary. The cost of disease management was converted from Hungarian Forint to Euros at an exchange rate of $276 \mathrm{ft}$ to $€ 1[24]$.

\section{Other Country Specific Data}

Other factors assumed to vary by setting included smoking prevalence as obtained from a report of tobacco risks factors across the EU [25], and the underlying all-cause risk of mortality used to inform the risk of cause-specific mortality in the model, as obtained from respective national life tables.

\section{Analysis}

For the base case, the economic and health benefit of adding varenicline to a 12 -week, once weekly, counselling program measuring cost-effectiveness from the payer's perspective was considered. Direct costs associated with medical treatment as borne by the healthcare provider or sickness fund were included. A secondary analysis was conducted from a societal perspective, including indirect costs. The results of the model are represented by incremental cost-effectiveness ratio (ICER), measured by the difference in costs divided by the difference in effectiveness. All cost values used in the model were reported in Euros for the year 2010. Cost estimates reported prior to 2010 were uprated using local inflation indices. Incremental effectiveness was measured using life year (LY) gained and quality adjusted-life year (QALY) gained. Cost and outcomes were discounted at $3.0 \%$ per year.

Uncertainty in the outcomes of the model was assessed using disease subgroup analysis and both one-way and probabilistic sensitivity analysis (PSA). Subgroup analysis included the evaluation of each disease; PVD, CHD, stroke. Sensitivity analyses included; 1) 10-year time horizon, 2) 20 year time horizon, 3 ) the cost of PVD and stroke, and PVD and CHD equal to either stable stroke or stable CHD, assuming no additional cost for managing PVD and 4) cost of stable stroke and CHD co-morbidity assumed equal to the sum of costs for stable stroke and stable CHD, thereby assuming patients receive mutually exclusive treatment for each condition. Outcomes from the PSA included costeffectiveness acceptability curves and cost-effectiveness planes.

\section{RESULTS}

\section{Base Case Results}

The costs, LY and QALYs for a cohort of 1000 patients are summarised in Table 2. Across countries, the incremental cost of health care management varied between $€ 388000$ and $€ 855000$, with incremental QALYs between 106 and 146. The corresponding incremental LY gained ranged between 135 and 187 . Results for incremental effect and incremental cost were consistent, with Germany having the highest cost and effect differences followed by Austria and Hungary. When including the cost of lost productivity, the incremental cost of varenicline and counselling versus 
Table 1. Cost of Disease Management by Health Condition and Setting, $\times 2010$ Costs

\begin{tabular}{|c|c|c|c|c|}
\hline Input (Reference) & Austria & Germany & Hungary & Health Utility \\
\hline Stroke (First year) & $\begin{array}{l}3722 \\
{[26]}\end{array}$ & $\begin{array}{c}20465 \\
{[27]}\end{array}$ & $\begin{array}{c}1532 \\
\text { (data on file) }\end{array}$ & $\begin{array}{l}0.15 \\
{[28]}\end{array}$ \\
\hline Stroke (Subsequent year) & $\begin{array}{l}1101 \\
{[26]}\end{array}$ & $\begin{array}{l}6055 \\
{[27]}\end{array}$ & $\begin{array}{c}2010 \\
\text { (data on file) }\end{array}$ & $\begin{array}{c}0.74 \\
{[29,30]}\end{array}$ \\
\hline CHD (first year) & $\begin{array}{r}2085 \\
{[26]}\end{array}$ & $\begin{array}{l}4955 \\
{[31]}\end{array}$ & $\begin{array}{c}1670 \\
\text { (data on file) }\end{array}$ & $\begin{array}{c}0.76 \\
{[32,33]}\end{array}$ \\
\hline Peripheral Vascular Disease (PVD) & $\begin{array}{c}2245 \\
{[26]}\end{array}$ & $\begin{array}{c}2832 \\
{[34,35]}\end{array}$ & $\begin{array}{c}922 \\
\text { (assumption) }\end{array}$ & $\begin{array}{l}0.79 \\
{[36]}\end{array}$ \\
\hline Stroke and CHD co-morbidity (First year) & $3722^{b}$ & $20465^{\mathrm{b}}$ & $1670^{\mathrm{b}}$ & $0.15^{\mathrm{b}}$ \\
\hline Lung Cancer & $\begin{array}{r}2209 \\
{[26]}\end{array}$ & $\begin{array}{c}9344 \\
{[34,35]}\end{array}$ & $\begin{array}{c}3874 \\
\text { (data on file) }\end{array}$ & $\begin{array}{l}0.61 \\
{[37]}\end{array}$ \\
\hline Mouth Cancer & $\begin{array}{l}1818 \\
{[26]}\end{array}$ & $\begin{array}{c}7384 \\
{[34,35]}\end{array}$ & $\begin{array}{c}3123 \\
\text { (assumption) }\end{array}$ & $\begin{array}{l}0.78 \\
{[38]}\end{array}$ \\
\hline COPD & $\begin{array}{l}1858 \\
{[26]}\end{array}$ & $\begin{array}{c}2244 \\
{[39]}\end{array}$ & $\begin{array}{c}815 \\
\text { (data on file) }\end{array}$ & $\begin{array}{c}0.76 \\
{[40,41]}\end{array}$ \\
\hline Annual unit cost of Lost productivity & $\begin{array}{c}17394 \\
{[22,23]}\end{array}$ & $\begin{array}{c}15873 \\
{[22,23]}\end{array}$ & $\begin{array}{c}3016 \\
{[22,23]}\end{array}$ & - \\
\hline
\end{tabular}

Note: ${ }^{a}$ Assumed equal to the health utility of first-year CHD.

${ }^{b}$ Maximum of stroke and CHD costs, or the minimum of stroke and CHD health utilities.

${ }^{\mathrm{c}}$ Cost of CHD adjusted by relative cost of PVD and CHD from Margolis et al., [21].

${ }^{\mathrm{d}}$ Minimum of PVD and stroke or PVD and CHD health utilities.

placebo and counselling varied between -€1600000 and $€ 230000$, representing a cost saving in favour of varenicline.

From a payer's perspective, the ICER ranged between $€ 3000$ and $€ 6000$ per QALY gained. The ICER for Austria was in terms of LY gained (or QALY gained) $€ 4112$ (€5 278), compared to $€ 2507$ ( $€ 3$ 183) and $€ 4567$ (€5 867) in Hungary and Germany, respectively.

\section{Sensitivity Analysis}

The results of the one-way sensitivity analysis and subgroup analysis are summarised in Table 3. By disease, varenicline was more cost-effective versus placebo in patients with $\mathrm{CHD}$ at baseline, and less cost-effective in patients with stroke for Hungary and Germany, and patients with PVD for Austria. Results from the sensitivity analyses showed marginal changes in ICER across all settings (Table 3).

Results from the PSA are shown in Figs. (2, 3). Overall, varenicline remained cost-effective in all iterations under a threshold of $€ 12500$ per QALY gained. All iterations remained in the more costly and more effective quadrant of the cost-effectiveness plane.

\section{DISCUSSION}

The aim of the study was to evaluate the costeffectiveness of varenicline and counselling versus placebo and counselling in patients with stable CVD. In summary, the results of the decision analytical model demonstrate that from a payer's perspective varenicline and counselling may increase life expectancy and quality of life, in exchange for an increase in cost due to drug acquisition and prolonged time on maintenance treatment, compared to placebo. Overall, the additional cost of intervention was partially offset by the gain in life expectancy and reduction in events over a cohort's lifetime. The resulting ICERs of Varenicline and counselling compared to placebo and counselling was $€ 4$ 112, €2 507 and $€ 4567$ per LY gained and $€ 5$ 278, €3 183 and $€ 5867$ per QALY gained for the Austrian, Hungarian and German settings, respectively. From a societal perspective, varenicline was found to dominate over all placebo with cost-savings in addition to benefits in LY and QALYs gained.

Results across settings were consistent, with only marginal variations between countries. This was to be expected given the need to apply common parameters for variables such as baseline risk of disease and mortality and relative risk of events based on smoking status. Variability between countries in baseline risk was therefore derived solely through the difference in smoking prevalence. This difference resulted in variability in smoking specific disease risks, given that smoking prevalence rates were applied to disaggregate risks by smoking status.

Additional differences included the cost of smokingrelated disease management, and country-specific factors such as underlying all-cause mortality. In this case, the higher cost of disease management and improved life 
Table 2. Modelled Costs and Health Outcome for a Cohort of 1000 Smokers Over a Lifetime

\begin{tabular}{|c|c|c|c|c|c|c|c|c|c|c|}
\hline \multirow[t]{2}{*}{ Country } & \multirow[t]{2}{*}{ Indication } & \multirow[t]{2}{*}{$\begin{array}{l}\text { Total Health } \\
\text { Care Costs }\end{array}$} & \multirow[t]{2}{*}{$\begin{array}{l}\text { Life } \\
\text { Years }\end{array}$} & \multirow[t]{2}{*}{ QALY } & \multirow[t]{2}{*}{$\begin{array}{l}\text { Incremental } \\
\text { Life-Years } \\
\text { Gained }\end{array}$} & \multirow[t]{2}{*}{$\begin{array}{c}\text { Incremental } \\
\text { QALY }\end{array}$} & $\begin{array}{l}\text { Incremental } \\
\text { Cost }\end{array}$ & $\begin{array}{l}\text { Incremental } \\
\text { Cost Per } \\
\text { Life- Gained }\end{array}$ & $\begin{array}{c}\text { Incremental } \\
\text { Cost Per } \\
\text { QALY Gained }\end{array}$ & \multirow{2}{*}{$\begin{array}{c}\begin{array}{c}\text { Incrementa } \\
\text { Cost }\end{array} \\
\text { Societal }\end{array}$} \\
\hline & & & & & & & \multicolumn{3}{|c|}{ Payer } & \\
\hline \multicolumn{11}{|l|}{ Austria } \\
\hline & $\begin{array}{l}\text { Varenicline and } \\
\text { Counselling }\end{array}$ & $€ 17,730,771$ & 7175 & 5316 & 184.9 & 144.1 & $€ 760,243$ & $€ 4,112$ & $€ 5,278$ & $-€ 1,631,857$ \\
\hline \multicolumn{11}{|l|}{ Hungary } \\
\hline & $\begin{array}{l}\text { Varenicline and } \\
\text { Counselling }\end{array}$ & $€ 6,110,250$ & 6094 & 4511 & 135.2 & 106.5 & $€ 338,911$ & $€ 2,507$ & $€ 3,183$ & $-€ 231,063$ \\
\hline & $\begin{array}{l}\text { Placebo and } \\
\text { Counselling }\end{array}$ & $€ 5,771,339$ & 5958 & 4405 & & & & & & \\
\hline & $\begin{array}{l}\text { Placebo and } \\
\text { Counselling }\end{array}$ & $€ 31,423,185$ & 6891 & 5098 & & & & & & \\
\hline
\end{tabular}

Table 3. Incremental Cost Per QALY Gained

\begin{tabular}{|c|c|c|c|}
\hline Analysis & Austria & Hungary & Germany \\
\hline \multicolumn{4}{|l|}{ Base Case Analysis } \\
\hline- & $€ 5,278$ & $€ 3,183$ & $€ 5,867$ \\
\hline \multicolumn{4}{|l|}{ Sub-Group } \\
\hline CHD & $€ 3,924$ & $€ 2,762$ & $€ 4,452$ \\
\hline Stroke & $€ 4,481$ & $€ 3,388$ & $€ 10,278$ \\
\hline PVD & $€ 6,140$ & $€ 3,387$ & $€ 6,127$ \\
\hline \multicolumn{4}{|l|}{ Sensitivity } \\
\hline 10-year time horizon & $€ 7,577$ & $€ 4,583$ & $€ 6,324$ \\
\hline 20-year time horizon & $€ 5,614$ & $€ 3,337$ & $€ 5,869$ \\
\hline $\mathrm{PVD} /$ Stroke and PVD/CHD maintenance costs equal to CHD and Stroke maintenance costs & $€ 4,816$ & $€ 3,103$ & $€ 5,810$ \\
\hline Stroke and CHD co-morbidity equal to sum of costs for Stroke and CHD states & $€ 5,220$ & $€ 3,124$ & $€ 5,739$ \\
\hline
\end{tabular}

expectancy in Germany, compared to Hungary and Austria, resulted in an increase in life expectancy for patients with CVD in Germany and more time receiving more expensive medical care.

Results of the sub-group analysis demonstrated that smoking cessation with varenicline in subjects with baseline stable CHD were marginally more cost-effective to treat than subjects with baseline stroke or PVD. This is due to the high risk of acute stroke following CHD in smokers compared to quitters, combined with the high cost of managing the acute stroke event.

Results of the sensitivity analyses showed little variation based on alternative assumptions however did show slightly higher ICERs for shorter time horizons. Results from the PSA showed that all iterations fell in the more costly and more effective quadrant of the cost-effectiveness plane.
Furthermore, the relationship between incremental cost and incremental effect was approximately linear, indicating that an increase in incremental cost was often associated with an increase in incremental QALY. In this case, incremental cost and incremental QALYs were driven by improved life expectancy. The driver of this was treatment effect.

The model presented in this study is limited by several factors. Firstly, we permitted one quit attempt during the time horizon of the model, assumed at baseline. Secondly, only one additional acute CVD event was modelled. In clinical practice, patients may undertake multiple quit attempts, and multiple acute non-fatal events may occur. Evidence to model the risk of disease beyond a second acute event is limited, and the relationship between the probabilities of achieving abstinence based on successive quit attempts is not well understood in this population. In the 


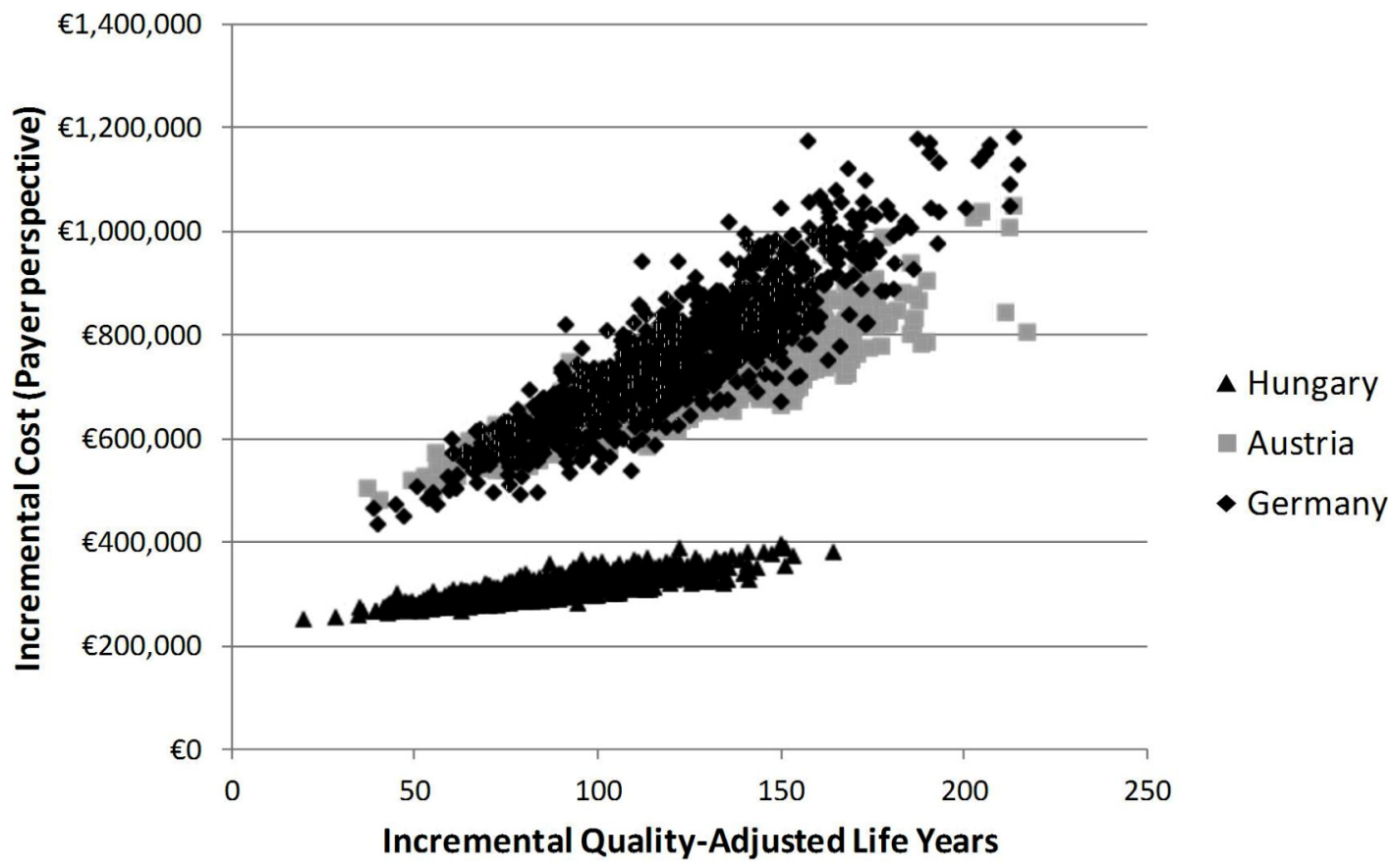

Fig. (2). Cost-effectiveness plane comparing varenicline and counselling to placebo and counselling from the payer perspective in Austria, Hungary and Germany.

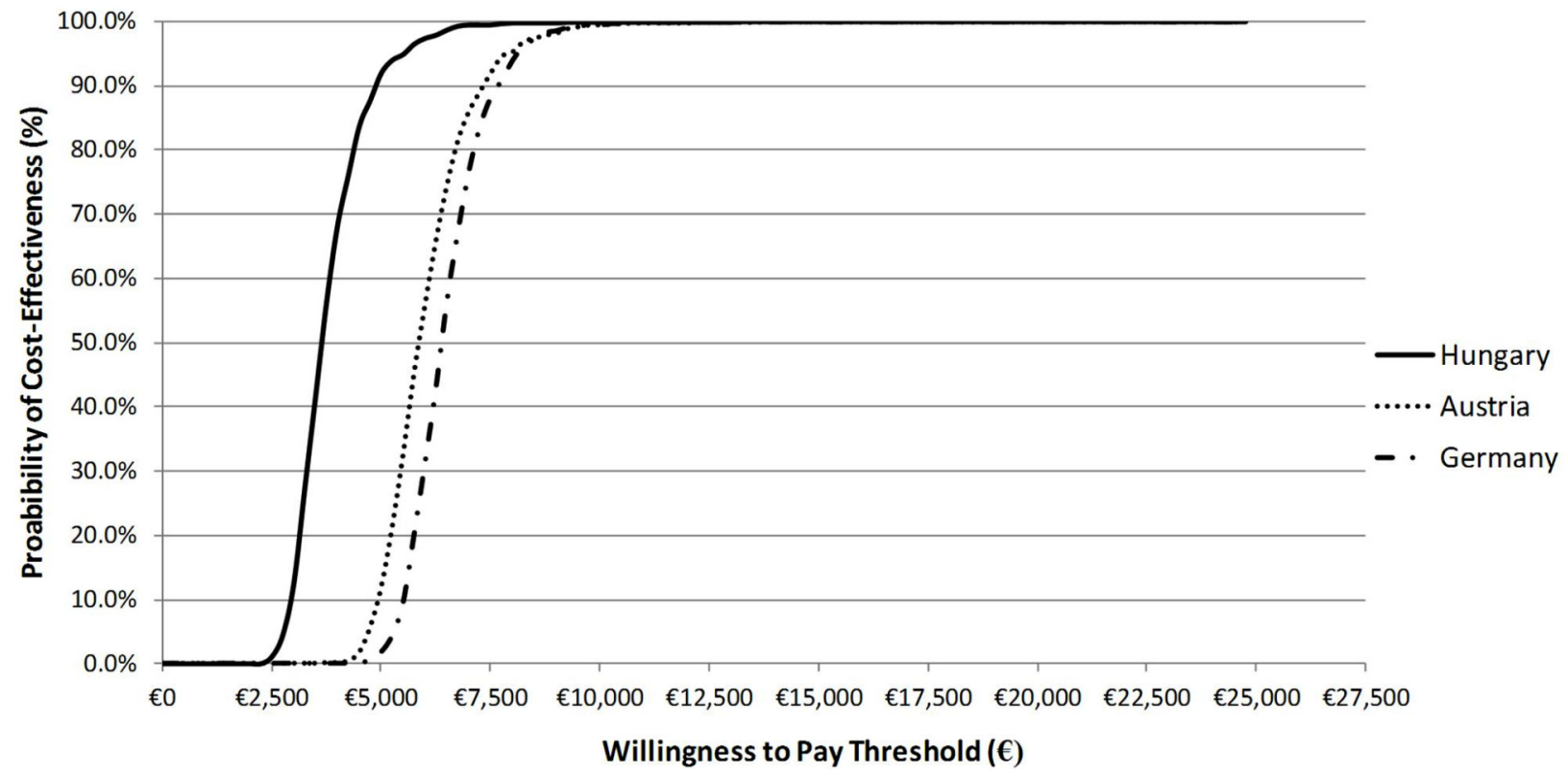

Fig. (3). Cost-effectiveness Acceptability Curve (per QALY gained) comparing varenicline and counselling versus placebo and counselling from the payer perspective in the Austria, Hungary and Germany.

absence of data, this was considered beyond the scope of this study.

Limitations in the evidence base, relating to countryspecific and CVD-specific data sources should also be considered. To overcome this, various assumptions were applied in the model and when researching model parameters. These include the use of common underlying disease risks for the estimation of smoking-specific and agespecific disease risks by country. In reality, such factors may vary due to environmental and cultural differences between countries. Evidence to quantify the direction or magnitude of such variations was not found.
Missing health state costs were also estimated based on the available data and assumptions felt to be adequate given the available information. To test the sensitivity of these assumptions, sufficiently different yet plausible assumptions were considered. Results of these analyses demonstrated that outcomes were not sensitive to our assumptions. However, in the absence of data, the limitations of such assumptions should be taken into consideration when evaluating the outcomes of the model.

The economic impact of CVD may also be underestimated, through the use of hospital databases and statistics not specific to patients with CVD. In the former, 
the cost of disease management may be higher than those used in the model and thus may increase the additional cost in maintaining those with CVD for longer. In the latter, the cost of lost productivity as measured from the general population, may overestimate the cost savings from a societal perspective, thus changing the cost-effectiveness of varenicline. In both cases, the expected magnitude of change in cost parameters is not expected to change the conclusions of the model.

The results of this economic evaluation closely follow the results reported by Wilson et al., comparing varenicline plus counselling to placebo plus counselling in patients with CVD in Spain, Italy, Portugal and Belgium [10], and the more general results comparing varenicline to alternative therapies in various populations, as reported in Zimovetz et al., [9]. As with Wilson et al., [10], the Markov model reported in this paper is based on an adjusted version of the previously published BENESCO model [11], and the extrapolation of outcomes from a single randomized placebo-controlled trial for varenicline plus brief counselling [8]. In contrast to Wilson et al., cost parameters for various states of morbidity in Austria, Hungary and Germany were lacking, requiring the use of novel adjustment methods based on existing or equivalent data from related countries.

In summary, the benefit of smoking cessation in patients with CVD is a necessary and major component of cardiac rehabilitation. The risk of further cardiovascular events has been shown to decline rapidly following smoking cessation, with some mechanisms of CVD such as increased platelet activation shown to reverse within days or weeks [42]. In the short-term patients will benefit from a reduced risk of mortality. In the long-term, this study has demonstrated that varenicline and counselling is a cost-effective strategy compared to placebo and counselling in patients with stable CVD.

\section{ACKNOWLEDGEMENT}

This study was sponsored by Pfizer Inc. The lead author, Robert Hettle, works for HERON Evidence Development Ltd, an independent consultancy tasked to develop the model and manuscript in co-authorship with Pfizer.

\section{CONFLICT OF INTEREST}

Declared none.

\section{ABBREVIATIONS}

$\begin{array}{ll}\text { CVD } & =\text { Cardiovascular disease } \\ \text { LY } & =\text { Life years } \\ \text { QALY } & =\text { Quality-adjusted life years } \\ \text { ICER } & =\text { Incremental cost-effectiveness ratio } \\ \text { CHD } & =\text { Coronary heart disease } \\ \text { DALY } & =\text { Disability adjusted life year } \\ \text { WHO } & =\text { World Health Organization } \\ \text { EU } & =\text { European Union } \\ \text { GDP } & =\text { Gross domestic product }\end{array}$

EUROASPIRE III = European Action on Secondary and Primary Prevention through Intervention to Reduce Events

COPD

$=$ Chronic Obstructive Pulmonary Disease

PVD

$=$ Peripheral Vascular Disease

SAMMEC

= Smoking-Attributable Mortality, Morbidity, and Economic Cost

BENESCO = Benefits of Smoking Cessation on Outcomes

\section{REFERENCES}

[1] World Health Organization. The European tobacco control report 2007

[2] The ASPECT consortium. Tobacco or Health in the European Union: Past, Present and Future 2004.

[3] U.S.Department of Health and Human Services, Centers for Disease Control and Prevention, National Center for Chronic Disease Prevention and Health Promotion, Office on Smoking and Health. The Health Consequences of Smoking: A report of Surgeon General 2004 May 27.

[4] Critchley J, Capewell S. Smoking cessation for the secondary prevention of coronary heart disease. Cochrane Database Syst Rev 2004; (1): CD003041.

[5] Kotseva K, Wood D, De BG, De BD, Pyorala K, Keil U. EUROASPIRE III: a survey on the lifestyle, risk factors and use of cardioprotective drug therapies in coronary patients from 22 European countries. Eur J Cardiovasc Prev Rehabil 2009; 16(2): 121-37.

[6] Banegas JR, Lopez-Garcia E, Dallongeville J, et al. Achievement of treatment goals for primary prevention of cardiovascular disease in clinical practice across Europe: the EURIKA study. Eur Heart J 2011; 32(17): 2143-52.

[7] Dallongeville J, Banegas JR, Tubach F, et al. Survey of physicians' practices in the control of cardiovascular risk factors: the EURIKA study. Eur J Cardiovasc Prev Rehabil 2011 [Epub ahead of print].

[8] Rigotti NA, Pipe AL, Benowitz NL, Arteaga C, Garza D, Tonstad S. Efficacy and safety of varenicline for smoking cessation in patients with cardiovascular disease: a randomized trial. Circulation 2010; 121(2): 221-9.

[9] Zimovetz EA, Wilson K, Samuel M, Beard SM. A review of costeffectiveness of varenicline and comparison of cost-effectiveness of treatments for major smoking-related morbidities. J Eval Clin Pract 2011; 17(2): 288-97.

[10] Wilson K, Hettle R, Marbaix S, et al. An economic evaluation based on a randomized placebo-controlled trial of varenicline in smokers with cardiovascular disease: results for Belgium, Spain, Portugal, and Italy. Eur J Cardiovasc Prev Rehabil 2011 [Epub ahead of print].

[11] Howard P, Knight C, Boler A, Baker C. Cost-utility analysis of varenicline versus existing smoking cessation strategies using the BENESCO Simulation model: application to a population of US adult smokers. Pharmacoeconomics 2008; 26(6): 497-511.

[12] U.S.Department of Health and Human Services, Centers for Disease Control and Prevention. Smoking-Attributable Mortality,Morbidity, and Economic Costs (SAMMEC). Available at: http://apps nccd cdc gov/sammec/index asp 2010 February 8. Available from: URL: http://apps.nccd.cdc.gov/sammec/index.asp

[13] Allender S, Peto V, Scarborough P, Kaur A, Rayner M. Coronary heart disease stastistics 2008 Edition. 1 ed. British Heart Foundation 2008.

[14] UK Lung Cancer incidence statistics. Cancer Research UK 2009 June 18. Available from: http://info.cancerresearchuk.org/ cancerstats/types/lung/incidence/

[15] Thun MJ, Apicella LF, Henley SJ. Smoking $v s$ other risk factors as the cause of smoking-attributable deaths: confounding in the courtroom. JAMA 2000; 284(6): 706-12.

[16] Abbott RD, Petrovitch H, Rodriguez BL, et al. Ankle/brachial blood pressure in men $>70$ years of age and the risk of coronary heart disease. Am J Cardiol 2000; 86(3): 280-4.

[17] Herlitz J, Bengtson A, Hjalmarson A, Karlson BW. Smoking habits in consecutive patients with acute myocardial infarction: prognosis 
in relation to other risk indicators and to whether or not they quit smoking. Cardiology 1995; 86(6): 496-502.

[18] Ramsay LE, Williams B, Johnston GD, et al. British Hypertension Society guidelines for hypertension management 1999: summary. BMJ 1999; 319(7210): 630-5.

[19] Wetter DW, Cofta-Gunn L, Fouladi RT, Cinciripini PM, Sui D, Gritz ER. Late relapse/sustained abstinence among former smokers: a longitudinal study. Prev Med 2004 Dec; 39(6): 1156-63.

[20] Krall EA, Garvey AJ, Garcia RI. Smoking relapse after 2 years of abstinence: findings from the VA Normative Aging Study. Nicotine Tob Res 2002; 4(1): 95-100.

[21] Margolis J, Barron JJ, Grochulski WD. Health care resources and costs for treating peripheral artery disease in a managed care population: results from analysis of administrative claims data. J Manag Care Pharm 2005; 11(9): 727-34.

[22] OECD. Income Distribution - Inequality. OECD stat 2009 October 14. Available from: URL: http://stats3.oecd.org/WBOS/index.aspx

[23] EUROSTAT. Employment rate by gender. EUROSTAT 2009 July 29. Available from: URL: http://epp.eurostat.ec.europa.eu/tgm/ table.do?tab=table \&init $=1 \&$ plugin $=1 \&$ language $=$ en $\&$ pode $=$ tsiem 010

[24] Hungarian National Bank. Magyar Nemzeti Bank. Available at: www mnb hu 2009 December 1

[25] Zatonski W, Manczuk M, Sulkwoska U, HEM. Closing the Health Gap in the European Union 2004

[26] Austria. Leistungsorientierte Krankenanstaltenfinanzierung System cataloge. 2010. Available from: http://www.bmgfj.gv.at/ $\mathrm{cms} /$ site/standard.html?channel $=\mathrm{CH} 0719 \&$ doc $=\mathrm{CMS} 11595171185$ 26

[27] Kolominsky-Rabas PL, Heuschmann PU, Marschall D, et al. Lifetime cost of ischemic stroke in Germany: results and national projections from a population-based stroke registry: the Erlangen Stroke Project. Stroke 2006; 37(5): 1179-83.

[28] Gage BF, Cardinalli AB, Owens DK. Cost-effectivemess of preference-based anti-thrombotic therapy for patients with nonvalvular atrial fibrillation. Stroke 1998; 29: 1083-91.

[29] Duncan P W, Lai SM, Keighley J. Defining post-stroke recovery: implications for design and interpretation of drug trials. Neuropharmacology 2000; 39: 835-41.

[30] Tengs TO, Lin TH. A Meta-Analysis of Quality-of-Life Estimates for Stroke. Pharmacoeconomics 2003; 21(3): 191-200.
[31] Fuchs S, Klauss V, Dieterle C, Wasem J, Aidelsburger P. Behandlungskosten bei Myokaradinfarkt, Schlaganfall und Diabetes mellitus Typ 2 unter. Pharmacoecon German Res Articles 2008; 6(1): 1-76.

[32] Fryback DG, Dasbach EJ, Klein R, et al. The beaver dam health outcomes study: initial catalog of health-state quality factors. Med Decis Making 1992; 13: 89-102.

[33] American Heart Association. Heart Disease and Stroke Statistics 2005 Update. 2005.

[34] DRG weights - CHD. Available at: http://www g-drg de/cms/index php/inek site de/G-DRG-System_2009/Abschlussbericht_zur_Wei terentwicklung_des_G 2009 December 1

[35] Z-Bax. Available at: http://www wido de/zbax html/Dez 20092009 December 1

[36] Bosch JL, Hunink MG. Comparison of the Health Utilities Index Mark 3 (HUI3) and the EuroQol EQ-5D in patients treated for intermittent claudication. Qual Life Res 2000; 9(6): 591-601.

[37] Trippoli S, Vaiani M, Lucioni C, Messori A. Quality of life and utility in patients with non-small cell lung cancer. Quality-of-life Study Group of the Master 2 Project in Pharmacoeconomics. Pharmacoeconomics 2001; 19(8): 855-63.

[38] Downer MC, Jullien JA, Speight PM. An interim determination of health gain from oral cancer and precancer screening: 1. Obtaining health state utilities. Community Dent Health 1997; 14(3): 139-42.

[39] Nowak D, Dietrich ES, Oberender P, et al. [Cost-of-illness Study for the Treatment of COPD in Germany]. Pneumologie 2004; 58(12): 837-44.

[40] Spencer M, Briggs AH, Grossman RF, Rance L. Development of an economic model to assess the cost effectiveness of treatment interventions for chronic obstructive pulmonary disease. Pharmacoeconomics 2005; 23(6): 619-37.

[41] Mannino DM, Buist AS, Petty TL, Enright PL, Redd SC. Lung function and mortality in the United States: data from the first national health and nutrition examination survey follow up study. Thorax 2003; 58(5): 388-93

[42] Twardella D, Kupper-Nybelen J, Rothenbacher D, Hahmann H, Wusten B, Brenner H. Short-term benefit of smoking cessation in patients with coronary heart disease: estimates based on selfreported smoking data and serum cotinine measurements. Eur Heart J 2004; 25(23): 2101-8. 